ISSN 1518-3483

Licenciado sob uma Licença Creative Commons

(c) (1)

\title{
Autoavaliação e avaliação pelos pares: uma análise de pesquisas internacionais recentes
}

\author{
Self and peer assessment: an analysis of recent \\ international researches
}

\section{L'auto-évaluation et l'évaluation par les pairs: une étude sur les recherches internationales récentes}

\section{Carla Barroso da Costa*}

Université de Montréal, Montréal, Canadá

\section{Resumo}

Uma revisão de artigos publicados em dois periódicos internacionais - Assessment and Evaluation in Higher Education e Active Learning in Higher Education - sobre autoavaliação e avaliação pelos pares, nos últimos sete anos (2010-2016), é o objetivo maior deste estudo. Uma análise detalhada dos artigos coloca em evidência diversos benefícios ligados a esses processos de regulação tão presentes no desenvolvimento de metodologias ativas de aprendizagem, como o melhor desempenho dos estudantes nas disciplinas e maior interação entre os membros do grupo. No entanto, limites são também identificados, como

* CBC: PhD, e-mail: barroso_da_costa.carla@uqam.ca 
a necessidade de realizar retroações claras e pertinentes, assim como de associar os tópicos de estudo, para que esses processos de regulação façam sentido.

Palavras-chave: Autoavaliação. Avaliação pelos pares. Avaliação para a aprendizagem.

\begin{abstract}
A review of articles published in two international journals - Assessment and Evaluation in Higher Education and Active Learning in Higher Education on - self-assessment and peer assessment, over the last seven years (2010-2016), is the subject of this paper. A detailed analysis of the articles reveals several benefits related to these processes of regulation used intensively in active learning methodologies, such as the better performance of students in the subjects, and greater interaction among group members. However, limits are also identified to these processes of regulation, such as the need to carry out clear and pertinent feedbacks, as well as the association between the topics of study.
\end{abstract}

Keywords: Self-assessment. Peer assessment. Assessment for learning.

\title{
Résumé
}

L'étude des articles publiés dans deux revues internationales - Assessment and Evaluation in Higher Education et Active Learning in Higher Education - sur I'auto-évaluation et l'évaluation par les pairs, au cours des sept dernières années (2010-2016), est l'objectif de cette recherche. Une analyse détaillée des articles met en évidence plusieurs avantages associés à ces processus de régulation constamment développés lorsque les professeurs utilisent les méthodes d'apprentissage actif. Ainsi, une meilleure performance des étudiants dans les cours et une plus grande interaction entre les membres du groupe sont des exemples vérifiés par les articles. Cependant, des limites sont également identifiées, comme le besoin d'effectuer des rétroactions claires et pertinentes, ainsi que l'importance 
d'une association entre les contenus étudiés dans les cours pour que la régulation puisse être perçue comme importante par les étudiants.

Mots-clés: Auto-évaluation. Évaluation par les pairs. L'évaluation pour l'apprentissage.

\section{Introdução}

A relação entre a prática e a concepção de avaliação é largamente divulgada pelos trabalhos de pesquisa. Sabe-se que as práticas de avaliação desenvolvidas em sala de aula estão estreitamente relacionadas à cultura de avaliação adotada pelos professores (TARDIF, 1993; VILLAS BOAS, 2000). A forma como se avalia reflete o modo de ver os estudantes e interagir com eles. Assim, os professores que se alinham com a cultura mais conservadora da avaliação tendem a favorecer uma avaliação com foco no desempenho e no produto, geralmente usando um processo tradicional, como testes padronizados e exames escritos de múltipla escolha, ou de respostas objetivas, em que há pouca interação entre o discente e o docente. Os professores que, por sua vez, adotam uma linha mais construtivista de avaliação, procuram diversificar os processos avaliativos e colocam em evidência a aprendizagem baseada em situações significativas (MEYER, 1992) e autênticas (WIGGINS, 1993). Eles tendem, portanto, a utilizar métodos alternativos de avaliação, com a possibilidade de utilização de vários mecanismos de regulação, entre os quais está a retroação (feedback), como uma maneira de retroalimentar a aprendizagem.

As metodologias ativas são geralmente definidas como práticas pedagógicas que se comprometem a engajar o estudante no centro do processo de aprendizagem (PRINCE, 2004), envolvendo-o em tarefas que necessitam da utilização de funções cognitivas superiores, como a análise, a avaliação e a criação (WHITE et al., 2016). Análises críticas, dissertações, estudos de caso e resolução de problemas são alguns exemplos de tarefas de ordem complexa, que vão além do conhecimento e da compreensão e buscam, em muitos casos, uma aprendizagem colaborativa e cooperativa. 
Ao mesmo tempo, as metodologias ativas, dinâmicas e inovadoras não podem se distanciar de práticas avaliativas construtivistas, sob pena de não obterem o resultado esperado: a aprendizagem em profundidade por parte do estudante. A integração da avaliação à prática pedagógica é essencial ao desenvolvimento dos saberes e ao sucesso dos discentes (DURAND; CHOUINARD, 2012; LEDUC; BLAIS; RAÎCHE, 2012).

Desde 1980, vários estudos destacam a existência de uma relação estreita e inseparável entre o ato de avaliar e o ato de aprender (ALLAL, 2013; LIGHT; COX, 2001; SARRASIN, 2006). Isso significa que a forma como os estudantes preparam-se para a avaliação depende, em larga medida, da percepção deles sobre a avaliação (GIBBS; SIMPSON, 2004). De acordo com Romainville (2006, p. 38), "os estudantes são realmente 'guiados' pelas exigências do processo avaliativo". Nesse caso, a avaliação influencia a qualidade da aprendizagem (BIGGS; TANG, 2007; FERNANDES; FLORES; LIMA, 2010; PEREIRA; FLORES, 2012) e diz aos estudantes o que e como aprender, produzindo diferentes abordagens de aprendizagem (DREW, 2001).

Dois tipos de abordagem da aprendizagem surgem constantemente na literatura: a aprendizagem por superfície e a aprendizagem em profundidade (BIGGS, 1987; CÔTÉ et al., 2006; KEMBER et al., 1997). A primeira está relacionada com um processo de armazenamento e reprodução de um conteúdo factual, sem necessariamente estabelecer conexões entre os diversos saberes e ter como ambição maior uma aprendizagem contínua. Atuando em uma abordagem por superfície, os estudantes apresentam como foco o desempenho em termos de nota (ou pontuações) e o comprometimento ao aprender é relativamente "calculado" no sentido de obter a nota de passagem (JONES; GORRA, 2013). A abordagem de aprendizagem em profundidade está associada à intenção de integrar os saberes aprendidos e dar sentido à tarefa (GIJBELS; SEGERS; STRUYF, 2008; ROMANO, 1991). Os estudantes que a utilizam procuram constantemente respostas às questões, são curiosos e geralmente agem com grande autonomia. 
A aprendizagem ativa e a avaliação construtivista são, na verdade, processos que se desenvolvem conjuntamente, cuja finalidade maior é agir como preditores de uma aprendizagem em profundidade por parte dos estudantes. É razoável, portanto, afirmar que a prática da aprendizagem ativa requer a participação dos estudantes no próprio processo avaliativo, pois o aprender deve trazer consigo a possibilidade de errar, refletir, refazer, reanalisar, recontextualizar e transferir os saberes a situações novas. Tem-se, nesse caso, o que os autores chamam "avaliação para a aprendizagem", que consiste em práticas desenvolvidas pelos professores no sentido de orientar e promover a aprendizagem do estudante (LAVEAULT; ALLAL, 2016), propiciando a (re)alimentação do processo de aprendizagem (e de ensino), assim como a transferência de saberes (GIPPS, 1994).

A avaliação para a aprendizagem implica necessariamente a preparação dos estudantes para exercer julgamentos complexos sobre seu próprio trabalho e o de outros, bem como tomar decisões em circunstâncias incertas e imprevisíveis, similares àquelas que eles encontrarão no futuro (BOUD; FALCHIKOV, 2006). Nesse sentido, diferencia-se da avaliação da aprendizagem, geralmente acompanhada de uma nota, que simboliza uma dada performance, e na qual os erros penalizam os estudantes, os quais, nessa conjuntura, podem tornar-se relutantes em admitir as falhas cometidas (BIGGS; TANG, 2007).

A fim de explicar como as informações obtidas no processo de avaliação podem ser usadas para apoiar e melhorar a aprendizagem, encontra-se, como aspecto central, a regulação, a qual se refere a mecanismos cognitivos, sociais e motivacionais que levam a mudanças na aprendizagem e no comportamento. Tema central da avaliação formativa em pesquisas de língua francesa, a regulação é geralmente estudada envolvendo a interação dos estudantes com os professores, com seus pares (colegas), com materiais instrucionais ou mesmo com ferramentas de avaliação (ALLAL, 2010).

O processo de regulação ocorre por meio do que é conhecido como feedback, a realimentação da aprendizagem, aqui neste artigo 
denominado retroação. No ensino superior, a retroação tem sido cada vez mais utilizada, sendo compreendida como um elemento crucial para o desenvolvimento dos estudantes como aprendizes independentes e centrados em processos de autorregulação (BROWN, 2007; CRISP, 2007; HATTIE; TIMPERLEY, 2007). Muitos pesquisadores defendem a tese de que a retroação é a ferramenta mais poderosa da aprendizagem (BIGGS; TANG, 2007). A retroação é portanto uma resposta ou uma reação que auxilia a correção de falhas ou limites na realização de uma tarefa, indica o progresso feito pelo estudante e permite a melhoria do seu desempenho em situações futuras semelhantes.

As pesquisas sobre retroação dividem-se em dois grandes grupos: a autoavaliação e a avaliação por pares (ou colegas). A primeira ocorre quando o estudante faz julgamentos sobre sua própria aprendizagem, particularmente sobre sua realização e o resultado da sua aprendizagem (BOUD; FALCHIKOV, 1989). Já a segunda é um mecanismo pelo qual os estudantes consideram o valor, a qualidade ou o sucesso dos processos, produtos ou resultados de aprendizagem de seus pares ou colegas (TOPPING, 1998).

Este artigo tem como objetivo resumir e discutir criticamente uma seleção de estudos empíricos internacionais, cujo tema central é a retroação no ensino superior, enfatizando ações que levam em conta a participação ativa do estudante no processo avaliativo - as autoavaliações e as avaliações pelos pares.

\section{Metodologia}

Dois periódicos científicos internacionais foram escolhidos para o desenvolvimento deste estudo: Assessment and Evaluation in Higher Education e Active Learning in Higher Education. Dois motivos basearam essa opção: (i) ambos abordam um número extenso de publicações na área de avaliação da e para a aprendizagem, sendo constantemente citados em dissertações, teses e artigos científicos voltados à área 
da educação; (ii) não menos importante, apresentam fator de impacto considerado muito bom para revistas da área da educação, segundo o Journal of Citation Reports, variando entre 1,000 e 1,075.

Os artigos analisados são oriundos de publicações feitas entre janeiro de 2010 e dezembro de 2016. Esse período foi estabelecido no sentido de resgatar características de pesquisas recentes, propiciando uma análise bastante atualizada do conjunto de produções científicas da área. A identificação das publicações foi realizada por meio da conjugação das palavras-chave "feedback for learning" e "higher education". Do seu cruzamento, um conjunto de 106 publicações foi inicialmente detectado, sendo a grande maioria oriunda do periódico Assessment and Evaluation in Higher Education, com 97 artigos; 9 publicações eram do periódico Active Learning in Higher Education.

Os artigos selecionados foram aqueles de caráter empírico e cuja retroação envolvia, como ponto central, as práticas de autoavaliação e de avaliação pelos pares. Assim, numa análise inicial, 22 artigos de cunho teórico foram retirados. Em uma segunda análise mais detalhada, foram selecionados artigos que continham explicitamente a palavra "feedback" no título ou no resumo, cujo objetivo maior era avaliar processos de retroação em contextos de sala de aula. Assim, 28 artigos foram excluídos. Finalmente, numa terceira e última seleção, retiraram-se do estudo 44 artigos cujo objetivo era analisar a percepção dos estudantes no que tange à retroação fornecida pelos professores, sem sua participação ativa. Portanto, 12 artigos compuseram este estudo e relatam experiências de retroação, tendo a autoavaliação e a avaliação pelos pares como elementos principais das pesquisas.

\section{Resultados}

Do total de artigos em análise $(\mathrm{N}=12)$, oito estão focados na avaliação pelos pares (ASGHAR, 2010; CARTNEY, 2010; HODGSON; CHAN; LIU, 2014; MCMAHON, 2010; MULDER et al., 2014; NICOL; 
THOMSON; BRESLIN, 2014; SIMPSON; CLIFTON, 2016; YUCEL et al., 2014), três centram-se na autoavaliação (GIBBS; TAYLOR, 2016; HUANG, 2016; JAY; OWEN, 2016) e um analisa o processo de autoavaliação, bem como de avaliação pelos pares (GREZ et al., 2012).

Dos 12 artigos expostos no Quadro 1, quatro são do tipo qualitativo; cinco, do tipo quantitativo; e dois, do tipo misto (qualitativo e quantitativo). Eles retratam experiências realizadas em diversas partes do mundo, sendo cinco pesquisas desenvolvidas na Europa (ASGHAR, 2010; CARTNEY, 2010; GREZ; VALCKE; ROOZEN, 2012; MCMAHON, 2010; NICOL; THOMSON; BRESLIN, 2014), três na Oceania (MULDER et al., 2014; SIMPSON; CLIFTON, 2016; YUCEL et al., 2014), duas na Ásia (HODGSON; CHAN; LIU, 2014; HUANG, 2016), uma na América do Norte (GIBBS; TAYLOR, 2016) e uma na África (JAY; OWEN, 2016).

\section{Pontos fortes do processo de autoavaliação e da avaliação pelos pares evidenciados nos artigos}

Todos os artigos analisados colocam em evidência a importância da participação dos estudantes no processo avaliativo. Segundo os resultados das pesquisas, essa participação não só desencadeia uma maior autonomia por parte dos estudantes, como também provoca ações reflexivas na busca da transferência da aprendizagem e um melhor desempenho nas disciplinas (notas mais elevadas), ou mesmo encoraja o desenvolvimento de aspectos sociais a partir de aprendizagens partilhadas.

A pesquisa de Nicol, Thomson e Breslin (2014) relata o caráter comparativo dos processos de avaliação feitos pelos pares. Assim, nesta tarefa, quando os estudantes avaliam o desempenho dos colegas em relação ao padrão desejado (e informado pelo professor), automaticamente fazem uma reflexão sobre o próprio desempenho em relação a esse mesmo padrão. A conclusão dos pesquisadores é que as avaliações feitas pelos pares contribuem para a autorregulação da aprendizagem, ou seja, auxiliam o pensamento, o sentimento ou a execução elaborada e orientada pelos 
próprios estudantes para a realização dos seus objetivos (ZIMMERMAN, 2000). Os autores colocam em evidência a associação entre a participação dos estudantes em suas próprias avaliações e a metacognição, entendida como a consciência e a regulação dos processos cognitivos empreendidos pelos estudantes (DUARTE, 2004).

Quadro 1 - Artigos sobre a retroação da aprendizagem a partir de autoavaliações e avaliações pelos pares

(Continua)

\begin{tabular}{|c|c|c|c|}
\hline $\begin{array}{l}\text { Autor(es) e } \\
\text { ano }\end{array}$ & Objetivo do estudo & $\begin{array}{l}\text { Foco do estudo/ } \\
\text { metodologia }\end{array}$ & Principais conclusões \\
\hline $\begin{array}{l}\text { Asghar } \\
(2010)\end{array}$ & $\begin{array}{l}\text { Analisar as } \\
\text { percepções dos } \\
\text { estudantes sobre } \\
\text { o processo de } \\
\text { coaching recíproco. }\end{array}$ & $\begin{array}{l}\text { Aprendizagem } \\
\text { cooperativa em } \\
\text { pequenos grupos/ } \\
\text { pesquisa qualitativa } \\
\text { - grupo focal. }\end{array}$ & $\begin{array}{l}\text { O estudo sugere que a avaliação } \\
\text { pelos pares promove a } \\
\text { autonomia na aprendizagem, } \\
\text { como também encoraja os } \\
\text { aspectos sociais e a criação } \\
\text { de uma cultura em que a } \\
\text { aprendizagem é partilhada. }\end{array}$ \\
\hline $\begin{array}{l}\text { Cartney } \\
\text { (2010) }\end{array}$ & $\begin{array}{l}\text { Estudar o potencial } \\
\text { de avaliação por } \\
\text { pares como um } \\
\text { veículo para permitir } \\
\text { aos estudantes } \\
\text { a utilização da } \\
\text { retroação que } \\
\text { recebem. }\end{array}$ & $\begin{array}{l}\text { Análise das emoções } \\
\text { ligadas ao processo } \\
\text { de avaliação por } \\
\text { pares/pesquisa } \\
\text { qualitativa - grupo } \\
\text { focal. }\end{array}$ & $\begin{array}{l}\text { Os resultados destacam } \\
\text { o componente emocional } \\
\text { associado ao trabalho avaliado, } \\
\text { que vai desde sentimentos } \\
\text { de ansiedade até raiva em } \\
\text { relação aos estudantes que } \\
\text { não participam plenamente do } \\
\text { processo de retroação. }\end{array}$ \\
\hline $\begin{array}{l}\text { Gibbs e } \\
\text { Taylor } \\
\text { (2016) }\end{array}$ & $\begin{array}{l}\text { Verificar o } \\
\text { procedimento } \\
\text { avaliativo mais } \\
\text { eficaz no que tange } \\
\text { à aprendizagem } \\
\text { em um curso } \\
\text { online: a retroação } \\
\text { do professor } \\
\text { ao estudante } \\
\text { individualmente ou a } \\
\text { autoavaliação. }\end{array}$ & $\begin{array}{l}\text { Respostas a um } \\
\text { questionário de } 30 \\
\text { perguntas/pesquisa } \\
\text { quantitativa. }\end{array}$ & $\begin{array}{l}\text { Não há diferença entre os dois } \\
\text { métodos de retroação - pelo } \\
\text { menos no que tange ao curso } \\
\text { online de estatística de nível de } \\
\text { pós-graduação. Os estudantes } \\
\text { expostos a ambos os métodos } \\
\text { de retroação tiveram notas finais } \\
\text { semelhantes. }\end{array}$ \\
\hline
\end{tabular}


Quadro 1 - Artigos sobre a retroação da aprendizagem a partir de autoavaliações e avaliações pelos pares

(Continua)

\begin{tabular}{|c|c|c|c|}
\hline $\begin{array}{l}\text { Autor(es) e } \\
\text { ano }\end{array}$ & Objetivo do estudo & $\begin{array}{c}\text { Foco do estudo/ } \\
\text { metodologia }\end{array}$ & Principais conclusões \\
\hline $\begin{array}{l}\text { Grez, } \\
\text { Valcke e } \\
\text { Roozen } \\
(2012)\end{array}$ & $\begin{array}{l}\text { Verificar o acordo } \\
\text { entre a avaliação } \\
\text { profissional e a } \\
\text { avaliação pelos } \\
\text { pares em relação } \\
\text { a habilidades de } \\
\text { apresentação oral, } \\
\text { explorando as } \\
\text { percepções dos } \\
\text { estudantes. }\end{array}$ & $\begin{array}{l}\text { Utilização das } \\
\text { pontuações geradas } \\
\text { pelas grades de } \\
\text { avaliação relativas } \\
\text { às apresentações } \\
\text { orais/pesquisa } \\
\text { quantitativa. }\end{array}$ & $\begin{array}{l}\text { Comparação dos escores da } \\
\text { pontuação da avaliação do } \\
\text { professor e da avaliação de pares } \\
\text { apresentou uma relação positiva, } \\
\text { mas também com diferenças } \\
\text { críticas. Os resultados sugerem } \\
\text { que os pares e os professores } \\
\text { ainda interpretam os critérios } \\
\text { e indicadores da rubrica de } \\
\text { maneira diferente. Isso pode } \\
\text { ser explicado por diferenças de } \\
\text { experiência entre os atores. }\end{array}$ \\
\hline $\begin{array}{l}\text { Hodgson, } \\
\text { Chan e Liu } \\
(2014)\end{array}$ & $\begin{array}{l}\text { Investigar a } \\
\text { concepção e } \\
\text { implementação de } \\
\text { projetos de avaliação } \\
\text { por pares a partir } \\
\text { da orientação dos } \\
\text { professores. }\end{array}$ & $\begin{array}{l}\text { Trabalho em grupo } \\
\text { com estudantes } \\
\text { do primeiro ano } \\
\text { universitário/ } \\
\text { pesquisa mista - } \\
\text { questionário e grupo } \\
\text { focal. }\end{array}$ & $\begin{array}{l}\text { Os benefícios da avaliação por } \\
\text { pares podem ser evidenciados } \\
\text { a partir da melhoria do } \\
\text { desempenho dos estudantes } \\
\text { e das percepções positivas do } \\
\text { processo de aprendizagem por } \\
\text { eles. No entanto, estudantes } \\
\text { com diferentes níveis de } \\
\text { desempenho acadêmico } \\
\text { mostram graus variados de } \\
\text { confiança e compromisso com o } \\
\text { processo de revisão pelos pares. }\end{array}$ \\
\hline $\begin{array}{l}\text { Huang } \\
\text { (2016) }\end{array}$ & $\begin{array}{l}\text { Examinar as } \\
\text { autoavaliações } \\
\text { dos estudantes } \\
\text { de apresentações } \\
\text { capturadas em } \\
\text { arquivos de áudio } \\
\text { de um teste oral de } \\
\text { língua estrangeira. }\end{array}$ & $\begin{array}{l}\text { Apresentação oral } \\
\text { dos estudantes a } \\
\text { partir da produção } \\
\text { de áudio/pesquisa } \\
\text { qualitativa - análise } \\
\text { dos áudios. }\end{array}$ & $\begin{array}{l}\text { Sugere-se que os professores, } \\
\text { além de preparar a retroação } \\
\text { para estudantes individualmente, } \\
\text { atribuam tempo projetando } \\
\text { tarefas para facilitar a } \\
\text { autoavaliação e o autofeedback, } \\
\text { utilizando-os como base para } \\
\text { a instrução subsequente. No } \\
\text { entanto, não está claro como } \\
\text { efetiva ou rapidamente os } \\
\text { estudantes podem realmente } \\
\text { melhorar em áreas em que foi } \\
\text { verificada certa fragilidade. } \\
\text { Também não está claro com } \\
\text { que frequência a autoavaliação } \\
\text { deve ser repetida durante uma } \\
\text { disciplina. }\end{array}$ \\
\hline
\end{tabular}


Quadro 1 - Artigos sobre a retroação da aprendizagem a partir de autoavaliações e avaliações pelos pares

(Continua)

\begin{tabular}{|c|c|c|c|}
\hline $\begin{array}{l}\text { Autor(es) e } \\
\text { ano }\end{array}$ & Objetivo do estudo & $\begin{array}{l}\text { Foco do estudo/ } \\
\text { metodologia }\end{array}$ & Principais conclusões \\
\hline $\begin{array}{l}\text { Jay e Owen } \\
\text { (2016) }\end{array}$ & $\begin{array}{l}\text { Verificar se a } \\
\text { utilização de } \\
\text { oportunidades de } \\
\text { autoavaliação dos } \\
\text { estudantes está } \\
\text { relacionada a um } \\
\text { maior desempenho } \\
\text { de habilidades } \\
\text { psicomotoras. }\end{array}$ & $\begin{array}{l}\text { Trabalho em grupo } \\
\text { feito em dois } \\
\text { anos seguidos: } \\
\text { no primeiro ano, } \\
\text { o grupo não fez } \\
\text { autoavaliação } \\
\text { e, no segundo, } \\
\text { fez/pesquisa } \\
\text { quantitativa. }\end{array}$ & $\begin{array}{l}\text { A partir do estudo, é evidente } \\
\text { que o desempenho psicomotor } \\
\text { dos estudantes tende a mostrar } \\
\text { uma evolução quando dadas } \\
\text { oportunidades para garantir a } \\
\text { prática da autoavaliação. }\end{array}$ \\
\hline $\begin{array}{l}\text { McMahon } \\
\text { (2010) }\end{array}$ & $\begin{array}{l}\text { Relatar experiência } \\
\text { do uso combinado } \\
\text { da avaliação por } \\
\text { pares e de atividades } \\
\text { de aprendizagem } \\
\text { negociadas dentro } \\
\text { de um currículo } \\
\text { baseado em } \\
\text { resultados. }\end{array}$ & $\begin{array}{l}\text { Avaliação por pares, } \\
\text { associada à avaliação } \\
\text { dos monitores } \\
\text { universitários e de } \\
\text { um examinador } \\
\text { externo/pesquisa } \\
\text { qualitativa - estratos } \\
\text { das informações dos } \\
\text { estudantes. }\end{array}$ & $\begin{array}{l}\text { Os resultados colocam em } \\
\text { evidência o fato de que } \\
\text { os estudantes mais fracos } \\
\text { beneficiavam-se dos talentos de } \\
\text { seus colegas mais experientes. } \\
\text { A experiência desenvolveu } \\
\text { competências para uma } \\
\text { aprendizagem autônoma e } \\
\text { melhorou a capacidade dos } \\
\text { estudantes para julgar seu } \\
\text { próprio trabalho e o de seus } \\
\text { colegas, na medida em que as } \\
\text { perspectivas dos estudantes } \\
\text { sobre suas próprias capacidades } \\
\text { e potenciais foram alteradas para } \\
\text { melhor. }\end{array}$ \\
\hline $\begin{array}{l}\text { Mulder et } \\
\text { al. (2014) }\end{array}$ & $\begin{array}{l}\text { Estudar as } \\
\text { percepções dos } \\
\text { estudantes quanto } \\
\text { ao processo de } \\
\text { avaliação por pares } \\
\text { antes e depois } \\
\text { dela e o efeito da } \\
\text { experiência sobre o } \\
\text { desempenho (notas) } \\
\text { obtido. }\end{array}$ & $\begin{array}{l}\text { Avaliação por pares } \\
\text { a partir de uma } \\
\text { grade de avaliação } \\
\text { pontuada/pesquisa } \\
\text { mista - análise do } \\
\text { desempenho obtido } \\
\text { pelas grades de } \\
\text { avaliação e grupo } \\
\text { focal. }\end{array}$ & $\begin{array}{l}\text { Antes da experiência, muitos } \\
\text { estudantes expressaram } \\
\text { apreensão e interrogação sobre } \\
\text { a competência dos colegas em } \\
\text { exercer a avaliação. A avaliação } \\
\text { por pares mostrou pontuações } \\
\text { atribuídas pelos colegas (a } \\
\text { "autoridade" naquele momento) } \\
\text { consistentemente baixas, } \\
\text { sugerindo que as preocupações } \\
\text { com as capacidades deles podem } \\
\text { permanecer enraizadas. Os } \\
\text { estudantes que apresentavam } \\
\text { notas acima da média obtiveram } \\
\text { melhorias modestas em suas } \\
\text { notas por meio da avaliação } \\
\text { por pares, enquanto os } \\
\text { estudantes abaixo da média } \\
\text { experimentaram aumentos } \\
\text { expressivos em suas notas. }\end{array}$ \\
\hline
\end{tabular}


Quadro 1 - Artigos sobre a retroação da aprendizagem a partir de autoavaliações e avaliações pelos pares

(Continua)

\begin{tabular}{|c|c|c|c|}
\hline $\begin{array}{l}\text { Autor(es) e } \\
\text { ano }\end{array}$ & Objetivo do estudo & $\begin{array}{l}\text { Foco do estudo/ } \\
\text { metodologia }\end{array}$ & Principais conclusões \\
\hline $\begin{array}{l}\text { Nicol, } \\
\text { Thomson } \\
\text { e Breslin } \\
(2014)\end{array}$ & $\begin{array}{l}\text { Identificar os } \\
\text { diferentes benefícios } \\
\text { resultantes do } \\
\text { recebimento de } \\
\text { retroações de } \\
\text { colegas e avaliar } \\
\text { os trabalhos dos } \\
\text { colegas, bem como } \\
\text { obter uma visão } \\
\text { mais profunda } \\
\text { dos processos } \\
\text { cognitivos que são } \\
\text { ativados quando } \\
\text { os estudantes } \\
\text { participam do } \\
\text { processo avaliativo. }\end{array}$ & $\begin{array}{l}\text { Trabalhos individuais } \\
\text { em que cada } \\
\text { estudante teve } \\
\text { que fazer uma } \\
\text { autoavaliação, } \\
\text { bem como uma } \\
\text { avaliação de dois } \\
\text { colegas, seguindo } \\
\text { procedimento único/ } \\
\text { pesquisa mista. }\end{array}$ & $\begin{array}{l}\text { A apresentação de revisões } \\
\text { feitas pelos estudantes é vista } \\
\text { como benéfica, envolvendo-os } \\
\text { ativamente no pensamento } \\
\text { crítico, na aplicação de critérios } \\
\text { de avaliação, na reflexão e, } \\
\text { por isso, na transferência de } \\
\text { aprendizagem. Os estudantes } \\
\text { relatam que a avaliação pelos } \\
\text { pares envolve um processo } \\
\text { comparativo da representação } \\
\text { do próprio trabalho em relação } \\
\text { ao dos colegas. Essa comparação } \\
\text { desencadeia um processo } \\
\text { reflexivo, em que eles usam a } \\
\text { retroação obtida pelos colegas } \\
\text { para atualizar seus pensamentos } \\
\text { sobre suas próprias tarefas. }\end{array}$ \\
\hline $\begin{array}{l}\text { Simpson } \\
\text { e Clifton } \\
\text { (2016) }\end{array}$ & $\begin{array}{l}\text { Estudar as } \\
\text { percepções dos } \\
\text { estudantes sobre } \\
\text { a avaliação pelos } \\
\text { pares, assim como } \\
\text { sua capacidade de } \\
\text { realizar retroações } \\
\text { de qualidade aos } \\
\text { pares, a partir de } \\
\text { diferentes elementos } \\
\text { que compõem um } \\
\text { relatório. }\end{array}$ & $\begin{array}{l}\text { Questionário do } \\
\text { tipo Likert foi } \\
\text { utilizado para obter } \\
\text { as impressões dos } \\
\text { estudantes quanto } \\
\text { às avaliações pelos } \\
\text { pares. Além disso, as } \\
\text { grades de avaliação } \\
\text { utilizadas para } \\
\text { avaliar os relatórios } \\
\text { foram também } \\
\text { estudadas/pesquisa } \\
\text { quantitativa. }\end{array}$ & $\begin{array}{l}\text { Os resultados indicam que a } \\
\text { avaliação pelos pares minimiza } \\
\text { o potencial de plágio. Além } \\
\text { disso, a qualidade da retroação } \\
\text { fornecida pela avaliação dos } \\
\text { pares e as alterações feitas entre } \\
\text { o projeto inicial e o relatório final } \\
\text { indicaram que os estudantes não } \\
\text { tinham capacidade para avaliar } \\
\text { a qualidade das referências } \\
\text { nem fazer uma análise crítica } \\
\text { nos relatórios dos grupos. } \\
\text { Portanto, o desenvolvimento da } \\
\text { compreensão dos estudantes } \\
\text { sobre as referências e a análise } \\
\text { crítica antes do processo } \\
\text { de revisão pelos pares e } \\
\text { da submissão do relatório } \\
\text { preliminar tem o potencial de } \\
\text { melhorar significativamente a } \\
\text { qualidade da retroação pelos } \\
\text { pares e do relatório final do } \\
\text { grupo. }\end{array}$ \\
\hline
\end{tabular}


Quadro 1 - Artigos sobre a retroação da aprendizagem a partir de autoavaliações e avaliações pelos pares

(Conclusão)

\begin{tabular}{|c|c|c|c|}
\hline $\begin{array}{l}\text { Autor(es) e } \\
\text { ano }\end{array}$ & Objetivo do estudo & $\begin{array}{l}\text { Foco do estudo/ } \\
\text { metodologia }\end{array}$ & Principais conclusões \\
\hline $\begin{array}{l}\text { Yucel et al. } \\
\text { (2014) }\end{array}$ & $\begin{array}{l}\text { Investigar as } \\
\text { percepções dos } \\
\text { estudantes sobre } \\
\text { os componentes } \\
\text { do programa } \\
\text { Desenvolvimento } \\
\text { da Compreensão } \\
\text { da Avaliação para } \\
\text { a Aprendizagem } \\
\text { (DUAL). }\end{array}$ & $\begin{array}{l}\text { Respostas a um } \\
\text { questionário } \\
\text { e análise das } \\
\text { notas obtidas no } \\
\text { trabalho/pesquisa } \\
\text { quantitativa. }\end{array}$ & $\begin{array}{l}\text { No exercício de revisão pelos } \\
\text { pares, } 65 \% \text { dos estudantes } \\
\text { perceberam utilidade na } \\
\text { estratégia para melhorar seus } \\
\text { relatórios. As reações negativas } \\
\text { de uma minoria considerável } \\
\text { de estudantes destacam a } \\
\text { necessidade de comunicar } \\
\text { claramente as expectativas e } \\
\text { os benefícios da revisão por } \\
\text { pares, com foco nos possíveis } \\
\text { benefícios do processo de } \\
\text { avaliação pelos pares. }\end{array}$ \\
\hline
\end{tabular}

Hodgson, Chan e Liu (2014) realçam a associação entre a avaliação pelos pares e o engajamento cognitivo dos estudantes numa abordagem de aprendizagem em profundidade, assim como o aperfeiçoamento do desempenho dos estudantes. Segundo McMahon (2010), o aumento do desempenho na disciplina é percebido, sobretudo, por estudantes com performances mais fracas, uma vez que se beneficiam dos talentos dos colegas mais habilidosos.

Asghar (2010) e Cartney (2010) destacam o benefício da avaliação por pares no que tange à autonomia, ao sentimento de eficácia, à interação entre colegas e ao desenvolvimento de uma cultura de ajuda recíproca. Segundo Cartney (2010), os processos de avaliação pelos pares promovem o engajamento dos estudantes na busca de aspectos que possam contribuir para a melhoria da qualidade do trabalho, diminuindo a ansiedade que geralmente é gerada pelo processo avaliativo.

Jay e Owen (2016) reforçam a importância da autoavaliação em processos de aprendizagem psicomotora. Os pesquisadores afirmam que as rubricas de avaliação, projetadas pela equipe de ensino, devem permitir a transparência no processo de avaliação, contribuindo para uma autoavaliação pertinente e válida. 


\section{Limites das autoavaliações e das avaliações pelos pares apresentados nos artigos}

Alguns limites das autoavaliações e avaliações pelos pares encontram-se nos artigos analisados e deixam reflexões com relação à importância da qualidade da retroação recebida pelo estudante e ofertada ao colega, assim como da percepção da sua utilidade pelos estudantes. $\mathrm{Na}$ realidade, esses dois pontos são muito explorados em publicações internacionais da área.

Primeiramente, as pesquisas indicam que os estudantes consideram as retroações irrelevantes quando eles não são capazes de compreender os comentários recebidos, por serem ilegíveis, confusos ou enigmáticos (HANDLEY; WILLIAMS, 2011). Em segundo lugar, os estudantes pouco se engajam nos processos de retroação se não percebem a associação entre os tópicos ou módulos estudados. Se as retroações recebidas não favorecem o aperfeiçoamento da aprendizagem em tópicos de estudo futuros, ou seja, se os estudantes percebem os tópicos de estudo como dissociados uns dos outros, os processos retroativos são relatados, em grande parte, como inúteis (CARTNEY, 2010; GREZ; VALCKE; ROOZEN, 2012). Em terceiro lugar, os estudos apontam para o fato de que os estudantes sentem-se incapazes de realizar retroações se os critérios de avaliação não são claros e devidamente apresentados pelo professor e discutidos em grupo (NICOL, 2008; YUCEL et al., 2014).

O estudo de Mulder et al. (2014) expõe a apreensão de alguns estudantes quanto ao processo de avaliação pelos pares. Isso porque as "notas" recebidas por um certo grupo de estudantes mostraram-se baixas, o que acarretou inquietação sobre a capacidade dos colegas de realizar avaliações competentes. Os resultados da pesquisa sugerem que a experiência de avaliação pelos pares, quando percebida como negativa, pode trazer desconfianças com relação a esse sistema de retroação, podendo dificultar sua utilização futura.

O estudo de McMahon (2010) indica que a experiência de retroação foi mais bem recebida por estudantes com baixas notas do que 
por aqueles com notas altas, uma vez, segundo o autor, a diferença entre o desempenho observado e o esperado nos dois grupos de estudantes pode ser suficiente para provocar diferenças de percepção quanto aos benefícios da retroação.

\section{Considerações finais}

A literatura internacional é repleta de conclusões positivas em relação aos processos de retroação, que incluem a autoavaliação e a avaliação por pares. No entanto, sabe-se igualmente que a satisfação dos estudantes sobre as ações de retroação pode ser baixa em algumas experiências (HUANG, 2016; NICOL, 2008; PRICE et al., 2010). Uma parte expressiva da insatisfação dos estudantes em relação à retroação está ligada ao fato de que, muitas vezes, esta chega tarde para que eles possam melhorar seus desempenhos (JONES; GORRA, 2013; MORRIS; CHIKWA, 2014). São retroações oriundas de avaliações somativas, muitas vezes não relacionadas a tópicos de estudo futuros. Nesse caso, a percepção dos estudantes é que as retroações recebidas têm como foco único a justificativa do avaliador quanto à nota ou menção fornecida (HUANG, 2016).

Muitos são os modelos que apresentam a importância do caráter cíclico do processo de retroação (PANADERO; ALONSO-TAPIA, 2014). Neles, se tem a retroação como um processo que não termina na recepção pelo estudante dos comentários do professor ou dos colegas. Segundo Hendry, Bromberger e Armstrong (2011), a retroação necessita de um diálogo, um processo interativo que ocorre como um pingue-pongue construtivo ou uma forma ainda mais dinâmica - laços coconstrutivos conectando os participantes (ASKEW; LODGE, 2000). Esses modelos referem-se à retroação como alimentação direta ou mecanismo antecipatório (feed forward), em que os comentários servem a uma dinâmica baseada na reflexão-ação-reflexão e a comunicação é aberta e desejável (HENDRY; BROMBERGER; ARMSTRONG, 2011). 
Nesse contexto, um elemento fundamental da regulação destaca-se: o processo de autoavaliação não é similar ao processo de autocorreção. A autoavaliação permite a apreciação do próprio trabalho, do seu resultado, um olhar crítico sobre sua aprendizagem. É uma avaliação interna, em que o estudante é convidado a refletir sobre os aspectos que necessitam ser alterados, sendo também possível justificar escolhas e o caminho percorrido (SCALLON, 2004). A autocorreção é uma ação "guiada" pelos comentários, que mostram diretamente as falhas cometidas e direcionam as ações para respostas consideradas corretas.

No caso específico da avaliação por pares, um aspecto importante na análise dos artigos é que ela oferece muitos benefícios para o sucesso acadêmico, mas não é uma panaceia para resolver todas as questões que implicam a participação do estudante em sua própria avaliação. Isso significa dizer que, para alguns estudantes, a retroação pelos professores pode ser aquela percebida como a mais adequada. Orsmond e Merry (2013) sugerem que os estudantes mais avançados, devido à sua melhor habilidade no conteúdo aprendido, ganham mais com a retroação vinda do professor do que daquelas provenientes de seus colegas.

Finalmente, algumas possibilidades de futuras pesquisas podem ser verificadas a partir da análise do conjunto de estudos apresentados. Todos descrevem a percepção dos estudantes sobre o processo de autoavaliação e de avaliação pelos pares. Não foi identificado nenhum artigo cujo foco era a percepção dos professores sobre esse mesmo processo. Identifica-se, assim, o vasto campo para novas pesquisas a serem realizadas, não somente com foco na percepção do estudante, mas também do professor. É importante ressaltar que a revisão de literatura limitou-se a dois periódicos internacionais. Apesar de esse ser um limite da pesquisa, esses periódicos mostram-se importantes em pesquisas da área da educação, sendo inegável sua influência nos estudos do tema da avaliação para a aprendizagem. Assim, acredita-se que sejam referências importantes para uma análise consistente e atual do corpo de pesquisas empíricas realizadas internacionalmente.

Outro aspecto relevante é o fato de que nenhuma das pesquisas analisadas investigou o fenômeno da autoavaliação e da avaliação 
por pares analisando o aspecto multicultural que muitos países apresentam. Em 2013, segundo dados da Organização para Cooperação e Desenvolvimento Econômico (OCDE, 2013), estima-se um total de 4,3 milhões de estudantes internacionais em todo o mundo, sendo que $77 \%$ encontram-se em países membros da OCDE. Essas estatísticas sugerem a necessidade do aumento de estudos sobre a avaliação para a aprendizagem, as quais levam em conta contextos multiculturais, no sentido de responder a perguntas como: em que aspectos as percepções do estudante nativo e do estudante internacional sobre as autoavaliações e as avaliações por pares assemelham-se e se diferem? Respostas a essa questão seriam, sem dúvida, de interesse de toda a comunidade universitária, incluindo estudantes e professores, mas também auxiliariam discussões fundamentadas na necessidade da presença de políticas públicas direcionadas a contextos de inclusão em instituições universitárias.

\section{Referências}

ALLAL, L. Assessment and the regulation of learning. In: PETERSON, P.; BAKER, E.; MCGRAW, B. (Org.). International encyclopedia of education. Oxford: Elsevier, 2010. v. 3. p. 348-351.

ALLAL, L. Évaluation: un pont entre enseignement et apprentissage à l'université. In: ROMAINVILLE, M.; GOASOUÉ, R; VANTOUROUT, M. (Org.). Évaluation et enseignement supérieur. Bruxelles: De Boeck Supérieur, 2013. p. 21-40.

ASGHAR, A. Reciprocal peer coaching and its use as a formative assessment strategy for first-year students. Assessment and Evaluation in Higher Education, v. 35, p. 403-417, 2010.

ASKEW, S.; LODGE, C. Gifts, ping-pong and loops - linking feedback and learning. In: ASKEW, S. (Org.). Feedback for learning. London: Routledge Falmer, 2000. 
BIGGS, J. Student approaches to learning. Hawthorn: Australian Council for Educational Research, 1987.

BIGGS, J.; TANG, C. Teaching for quality learning at university. Buckingham: SHRE; Open University Press, 2007.

BOUD, D.; FALCHIKOV, N. Quantitative studies of self-assessment in higher education: a critical analysis of findings. Higher Education, v. 18, p. 529-549, 1989.

BOUD, D.; FALCHIKOV, N. Aligning assessment with long-term learning. Assessment and Evaluation in Higher Education, v. 31, n. 4, p. 399-413, 2006.

BROWN, J. Feedback: the student perspective. Research in Post-Compulsory Education, v. 12, p. 33-51, 2007.

CARTNEY, P. Exploring the use of peer assessment as a vehicle for closing the gap between feedback given and feedback used. Assessment and Evaluation in Higher Education, v. 35, p. 551-564, 2010.

CÔTÉ, D. J. et al. L'approche d'apprentissage dans un curriculum médical préclinique basé sur l'apprentissage par problèmes. Recherche et Perspectives, v. 7, n. 4, p. 201-212, 2006.

CRISP, B. R. Is it worth the effort? How feedback influences students' subsequent submission of assessable work. Assessment and Evaluation in Higher Education, v. 32, p. 571-581, 2007.

DREW, S. Student perceptions of what helps them learn and develop. Higher Education, v. 6, n. 3, p. 309-331, 2001.

DUARTE, A. M. Auto-regulação e abordagens à aprendizagem. In: SILVA, A. S.; DUARTE, A. M.; VEIGA-SIMÃO, M. (Org.). Aprendizagem auto-regulada - perspectivas psicológicas e educacionais. Porto: Porto, 2004. p. 39-54.

DURAND, M. J.; CHOUINARD, R. (Org.). L'évaluation des apprentissages: de la planification à la communication des résultats. Montréal: Marcel Didier, 2012. 
FERNANDES, S.; FLORES, M. A.; LIMA, R. A aprendizagem baseada em projetos interdisciplinares: avaliação do impacto de uma experiência no ensino de engenharia. Avaliação, Campinas, v. 15, n. 3, p. 59-86, 2010.

GIBBS, G.; SIMPSON, C. Conditions under which assessment supports student learning. Learning and Teaching in Higher Education, v. 1, p. 3-31, 2004.

GIBBS, J. C.; TAYLOR, J. D. Comparing student self-assessment to individualized instructor feedback. Active Learning in Higher Education, v. 17, n. 2, p. 111-123, 2016.

GIJBELS, D.; SEGERS, M.; STRUYF, E. Constructivist learning environments and the (im)possibility to change students' perceptions of assessment demands and approaches to learning. Instructional Science, v. 36, p. 413-443, 2008.

GIPPS, C. Developments in educational assessment or what makes a good test? Assessment in Education, v. 1, p. 283-191, 1994.

GREZ, L.; VALCKE, M.; ROOZEN, I. How effective are self- and peer assessment of oral presentation skills compared with teachers' assessments? Active Learning in Higher Education, v. 13, n. 2, p. 129-142, 2012.

HANDLEY, K.; WILLIAMS, L. From copying to learning: using exemplars to engage students with assessment criteria and feedback. Assessment and Evaluation in Higher Education, v. 36, p. 95-108, 2011.

HATTIE, J.; TIMPERLEY, H. The power of feedback. Review of Educational Research, v. 77, p. 81-112, 2007.

HENDRY, G. D.; BROMBERGER, N.; ARMSTRONG, S. Constructive guidance and feedback for learning: the usefulness of exemplars, marking sheets and different types of feedback in a first year law subject. Assessment and Evaluation in Higher Education, v. 36, p. 1-11, 2011.

HODGSON, P.; CHAN, K.; LIU, J. Outcomes of synergetic peer assessment: first-year experience. Assessment and Evaluation in Higher Education, v. 39, n. 2, p. 168-178, 2014. 
HUANG, S. C. Understanding learners' self-assessment and self-feedback on their foreign language speaking performance. Assessment and Evaluation in Higher Education, v. 41, p. 803-820, 2016.

JAY, J.; OWEN, A. Providing opportunities for student self-assessment: the impact on the acquisition of psychomotor skills in occupational therapy students. Assessment and Evaluation in Higher Education, v. 41, p. 1176-1192, 2016.

JONES, O.; GORRA, A. Assessment feedback only on demand: Supporting the few not supplying the many. Active Learning in Higher Education, v. 14, n. 2, p. 149-161, 2013.

KEMBER, D. et al. Evaluating the effectiveness of educational innovations: using the study process question. Studies in Educational Evaluation, v. 23, n. 2, p. 141157, 1997.

LAVEAULT, D.; ALLAL, L. Implementing assessment for learning: theorical and practical issues. In: LAVEAULT, D; ALLAL, L. (Org.). Assessment for learning: meeting the challenge of implementation. Londres: Springer, 2016.

LEDUC, D.; BLAIS, J. G.; RAÎCHE, G. Intégration des pratiques d'évaluation des apprentissages aux pratiques pédagogiques dans le domaine des arts au collégial. Revue des Sciences de l'Éducation, v. 38, n. 2, p. 373-396, 2012.LIGHT, G.; COX, R. Learning and teaching in higher education: the reflective professional. London: Sage, 2001.

MCMAHON, T. Peer feedback in an undergraduate programme: using action research to overcome students' reluctance to criticise. Educational Action Research, v. 18, p. 273-287, 2010.

MEYER, C. A. What's the difference between authentic and performance assessment? Educational Leadership, v. 49, n. 8, p. 39-40, 1992.

MORRIS, C.; CHIKWA, G. Screencasts: how effective are they and how do students engage with them? Active Learning in Higher Education, v. 15, n. 1, p. 25-37, 2014. 
MULDER, R. et al. How does student peer review influence perceptions, engagement and academic outcomes? A case study. Assessment and Evaluation in Higher Education, v. 39, n. 6, p. 657-677, 2014.

NICOL, D.; THOMSON, A.; BRESLIN, C. Rethinking feedback practices in higher education: a peer review perspective. Assessment and Evaluation in Higher Education, v. 39, p. 102-122, 2014.

NICOL, D. Learning is a two-way street. Times Higher Education, 24 abr. 2008. Disponível em: <https://www.timeshighereducation.com/news/learning-is-a-two-way-street/401542.article>. Acesso em: 30 mar. 2017.

ORGANIZAÇÃO PARA COOPERAÇÃO E DESENVOLVIMENTO ECONÔMICO (OCDE). Education indicators in focus. Paris, 2013. Disponível em: <https://www. oecd.org/education/skills-beyond-school/EDIF\%202013--N\%C2\%B014\%20 (eng)-Final.pdf >. Acesso em: 10 abr. 2017.

ORSMOND, P.; MERRY, S. The importance of self-assessment in students' use of tutors' feedback: a qualitative study of high and non-high achieving Biology undergraduates. Assessment and Evaluation in Higher Education, v. 38, p. 737-753, 2013.

PANADERO, E.; ALONSO-TAPIA, J. How do students self-regulate? Review of Zimmerman's cyclical model of self-regulated learning. Anales de Psicología, v. 30, n. 2, p. 450-462, 2014.

PEREIRA, D. R.; FLORES, M. A. Percepções dos estudantes universitários sobre a avaliação das aprendizagens: um estudo exploratório. Avaliação, Campinas, v. 17, n. 2, p. 529-556, 2012.

PRICE, M. et al. Feedback: all that effort but what is the effect? Assessment and Evaluation in Higher Education, v. 35, p. 277-289, 2010.

PRINCE, M. Does active learning work? A review of the research. Journal of Engineering Education, v. 93, n. 3, p. 223-231, 2004. 
ROMAINVILLE, M. Quand la coutume tient lieu de compétence: les pratiques d'évaluation des acquis à l'université. In: COLET, N. R.; ROMAINVILLE, M. (Org.). La pratique enseignante en mutation à l'université: perspectives en éducation et formation. Bruxelles: De Boeck et Larcier, 2006, p. 19-40.

ROMANO, G. Étudier... en surface ou en profondeur? Pédagogie Collégiale, v. 5, n. 2, p. 6-11, 1991.

SARRASIN, L. L'évaluation: au cœur de l'enseignement et de l'apprentissage. Vie Pédagogique, v. 141, p. 47-53, 2006.

SCALLON, G. L'évaluation des apprentissages dans une approche par compétences. Saint-Laurent (Montréal): Éditions du Renouveau Pédagogique, 2004.

SIMPSON, G.; CLIFTON, J. Assessing postgraduate student perceptions and measures of learning in a peer review feedback process. Assessment and Evaluation in Higher Education, v. 41, p. 501-514, 2016.

TARDIF, J. L'évaluation dans le paradigme constructiviste. In: HIVO, H. (Org.). L'évaluation des apprentissages: réflexions, nouvelles tendances et formation. Sherbrooke: Éditions du CRP, 1993. p. 27-56.

TOPPING, K. Peer assessment between students in colleges and universities. Review of Educational Research, v. 68, n. 3, p. 249-276, 1998.

VILLAS BOAS, B. M. F. Avaliação no trabalho pedagógico universitário. In: CASTANHO, S.; CASTANHO, M. E. (Org.). O que há de novo na educação superior: do projeto pedagógico à prática transformadora. Campinas: Papirus, 2000.

WHITE, P. J. et al. Adopting an active learning approach to teaching in a research-intensive higher education context transformed staff teaching attitudes and behaviours. Higher Education Research and Development, v. 35, n. 3, p. 619-633, 2016.

WIGGINS, G. Assessing student performance: exploring the purpose and limits of testing. San Francisco: Jossey-Bass, 1993. 
YUCEL, R. et al. The road to self-assessment: exemplar marking before peer review develops first-year students' capacity to judge the quality of a scientific report. Assessment and Evaluation in Higher Education, v. 39, n. 8, p. 971-986, 2014. ZIMMERMAN, B. Attaining self-regulation: a social cognitive perspective. In: BOEKAERTS, M.; PINTRICH, P.; ZEIDNER, M. (Org.). Handbook of self-regulation. New York: Academic Press, 2000. p. 13-39.

Recebido: 04/11/2017

Received: 11/04/2017

Aprovado: 25/05/2017 Approved: 05/25/2017 
